\title{
Effectiveness of antioxidant nutraceuticals in attenuating canonical NF-kb signaling in human skeletal muscle resulting from exercise-induced inflammation and oxidative stress
}

\begin{abstract}
Oxidative stress is a process that produces cellular damage by oxidation of cellular components such as lipids, protein, and DNA. It is also a regulator of the acute phase inflammatory response, and also involves the production of reactive oxygen species (ROS) by mitochondrial respiratory activity and from the capillary endothelium in contracting skeletal muscles. Exercise-induced muscle damage is associated with an acute phase inflammatory response. This response results in the production of circulating pro-inflammatory cytokines such as tumor necrosis alpha (TNF- $\alpha$ ) which is a mediator of muscle wasting and acts through the stimulation of nuclear factor kappa B (NF- $\mathrm{BB})$. Skeletal muscle damage and injury becomes evident in many catabolic scenarios and is characterized by proteolysis and muscle wasting. Inflammation and oxidative stress are associated with skeletal muscle wasting in various disease states including cancer cachexia, muscular dystrophy, AIDS, sepsis, etc. Antioxidant supplementation has been suggested to attenuate exercise-induced oxidative stress and the subsequent activation of NF- $\kappa \mathrm{B}$ through various mechanisms; however, there is still conflicting evidence and more research needs to be completed to better understand the role of NF- $\kappa \mathrm{B}$ signaling in skeletal muscle. Antioxidant supplementation has also been shown to attenuate oxidative stress and the subsequent formation of reactive oxygen nitrogen species (ROS, RONS) in skeletal muscle. As a result, this area requires further research as this process has also been demonstrated to mediate NF- $\kappa B$ signaling. Prior evidence suggests that various nutraceutical supplements seem to play a beneficial role in maintaining muscle mass during periods of heightened inflammation and oxidative stress and possible muscle wasting.
\end{abstract}

Volume I Issue 6 - 2014

\section{Sarah McKinley, Darryn SWilloughby}

Department of Health, Human Performance and Recreation, Baylor University, USA

Correspondence: Darryn Willoughby, Department of Health, Human Performance, and Recreation, Baylor University, Waco, I312 S. 5th Street, P.O. Box 973।3,Waco,TX 7679873 I3, USA, Tel 2547103504,Email darryn_willoughby@baylor.edu

Received: November 0I, 2014 | Published: November 28, 2014

Keywords: oxidative stress, inflammation, skeletal muscle, proteolysis,

cytokine, antioxidant, nutraceutical

Abbreviations: ROS, reactive oxygen species; RONS, reactive oxygen nitrogen species; TNF, tumor necrosis factor; TNFR, tumor necrosis factor receptor; NF, nuclear factor; COPD, chronic obstructive pulmonary disease; RHD, rel homology domain; IL,

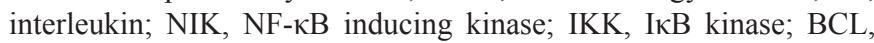
b-cell lymphoma; MOD, minimal oligomerization domain; LPS, lipopolysaccharide; RIP, receptor interacting protein; TRAF, tnfreceptor associated factor; TRADD, tnfr-associated death domain protein; c-IAP, cellular inhibitor of apoptosis protein; TAK1, tgf$\beta$-activated kinase 1 ; LT- $\beta$, lymphotoxin $\beta$; BAFF, b-cell activating factor; $\mathrm{CD}$, cluster of differentiating; MuRF1, murine ring finger-1; UPS, ubiquitin proteasome system; TWEAK, thf-like weak inducer of apoptosis; HSPs, heat shock proteins; NFAT, nuclear $t$ factor of activated $t$ cells

\section{Introduction}

Exercise preferentially biased with forced-lengthening (eccentric contractions) causes muscle damage, which is a manifestation of ultra-structural changes and protein degradation, and is associated with the development of an acute phase inflammatory response. ${ }^{1}$ This inflammatory response is a microvasculature-induced reaction characterized by the migration of serum proteins and leukocytes from the blood to the skeletal muscle. Involved in this migration are proinflammatory cytokines, most notably tumor necrosis factor alpha $(\mathrm{TNF}-\alpha)^{2}$ which binds its trans-membrane receptor in skeletal muscle and activates a transcription factor known as nuclear factor kappa $\mathrm{B}$ $(\mathrm{NF}-\kappa \mathrm{B})$. The activation of NF- $\kappa \mathrm{B}$ has been found to be a critical factor involved in the multifaceted homeostasis of muscle. This becomes important as the development and growth of skeletal muscle requires a complicated series of events that are regulated through various pathways. The plasticity of skeletal muscle is important to regulate the need for anabolic and catabolic processes, and any perturbation of these processes can lead to various muscle disorders associated with wasting. ${ }^{3}$

Furthermore, exercise-induced muscle damage is also associated with oxidative stress, a process that not only directly causes cellular damage by oxidation of cellular components such as lipids, protein, and DNA, but also acts as a regulator of the acute phase inflammatory response. Oxidative stress instigates the nuclear translocation of certain redox-sensitive transcription factors, pro-inflammatory cytokines, chemokines, and adhesion molecules. The resultant effect is phagocyte infiltration into skeletal muscle, thereby causing proteolysis, ultra-structural damage, and oxidative injury. During 
this cascade is the production of reactive oxygen species (ROS) by mitochondrial respiratory activity. In addition, due to the intermittent ischemia-reperfusion associated with exercise, xanthine oxidase is activated resulting in the formation of ROS by the capillary endothelium in contracting muscles. ${ }^{4}$

Skeletal muscle damage and injury becomes evident in many catabolic scenarios and is characterized by proteolysis and muscle wasting. Inflammation and oxidative stress are associated with skeletal muscle wasting in various disease states including cancer cachexia, muscular dystrophy, AIDS, sepsis, diabetes, chronic obstructive pulmonary disease (COPD), and cystic fibrosis..$^{5-9}$ Muscle wasting occurs as a result of a reduction in protein synthesis, an increase in protein degradation, or both. ${ }^{10-12}$ Various stimuli prompt skeletal muscle wasting through specific mechanisms and exercise-induced muscle damage is a fitting model for this process. While multiple signaling pathways are involved in the process of skeletal muscle wasting, recent evidence has suggested that NF- $\mathrm{KB}$ is one of the most important mechanisms because the activation of the NF- $\mathrm{kB}$ pathway stimulates muscle loss. ${ }^{5}$ The pro-inflammatory cytokine, TNF- $\alpha$, is a mediator of muscle wasting and acts through the stimulation of NF$\kappa B .5 \cdot{ }^{5,13}$ Recent evidence has shown that modification of NF- $\kappa B$ activity through pharmacogenetics can actually prevent skeletal muscle loss in various diseases, injury, and unloading. ${ }^{14-17}$

There is not an abundance of human studies demonstrating the role that antioxidant supplements may play in down-regulating $\mathrm{NF}-\kappa \mathrm{B}$ activity. However, enough evidence does exist suggesting a potential beneficial role for this type of nutraceutical supplementation. Therefore, it is feasible to review the potential for various antioxidant nutraceuticals on NF- $\mathrm{KB}$ activity, and the subsequent capacity they might possess in attenuating the effects of catabolic NF- $\mathrm{KB}$ activity, on oxidative stress and wasting in skeletal muscle. ${ }^{18-21}$ Therefore, the purpose of this brief review is to better understand the underlying mechanisms of NF- $\mathrm{kB}$ and its effects on oxidative stress and muscle wasting in humans, as well as possible antioxidant nutraceutical supplements that may attenuate these effects.

\section{NF $=\kappa B$ signaling pathway}

$\mathrm{NF}-\kappa \mathrm{B}$ is a ubiquitously expressed transcription factor that is considered vital to numerous cellular processes. ${ }^{3,22}$ It has been suggested that NF- $\mathrm{kB}$ directly modifies hundreds of gene products, including genes that encode cytokines, chemokines, cell adhesion molecules, growth factors, immunoregulatory receptors, acute-phase and stress response proteins, cell surface receptors, transcription factors, and several enzymes involved in protein degradation by the ubiquitin-proteasome system, as well as regulators of redox status, apoptosis, disuse atrophy, and host defense. ${ }^{5,23}$ This is summarized in Figure 1. The NF- $\mathrm{KB}$ family is comprised of five genes that code for protein subunits, RelA/p65, RelB, c-Rel, p50, and p52, which can be seen in Figure $2 \mathrm{~A} .{ }^{3,5,13,22}$ In humans, the proto-oncogene c-Rel is a protein that is encoded by the REL gene (v-rel avian reticuloendotheliosis viral oncogene homolog). The c-Rel protein is a member of the NF- $\mathrm{kB}$ family of transcription factors and contains a Rel homology domain (RHD) at its N-terminus and two C-terminal trans activation domains. As can be seen in Figure 2B, the IкB family consists of seven proteins including I $\mathrm{I} \mathrm{B} \alpha$, I $\mathrm{K} \mathrm{B} \beta, \mathrm{I} \kappa \mathrm{B} \varepsilon, \mathrm{I} \kappa \mathrm{B} \gamma, \mathrm{B}-\mathrm{cell}$ lymphoma 3-encoded protein (BCL-3), and precursor proteins p100 and $105 .{ }^{5,13,22,24}$ The most commonly described forms of NF- $\mathrm{kB}$ are the p50/p65 heterodimer and p50/p50 homodimer complexes, followed by $\mathrm{p} 50 / \mathrm{c}-\mathrm{Rel}$ and $\mathrm{p} 52 / \mathrm{RelB} .^{3,10}$ Unlike the other genes, p50 and p52 genes lack transcriptional activation domains, which generates $\mathrm{p} 50$ and $\mathrm{p} 52$ homodimers that function as gene repressors by blocking DNA consensus sites, which can be seen in Figure 3., 3,5,22

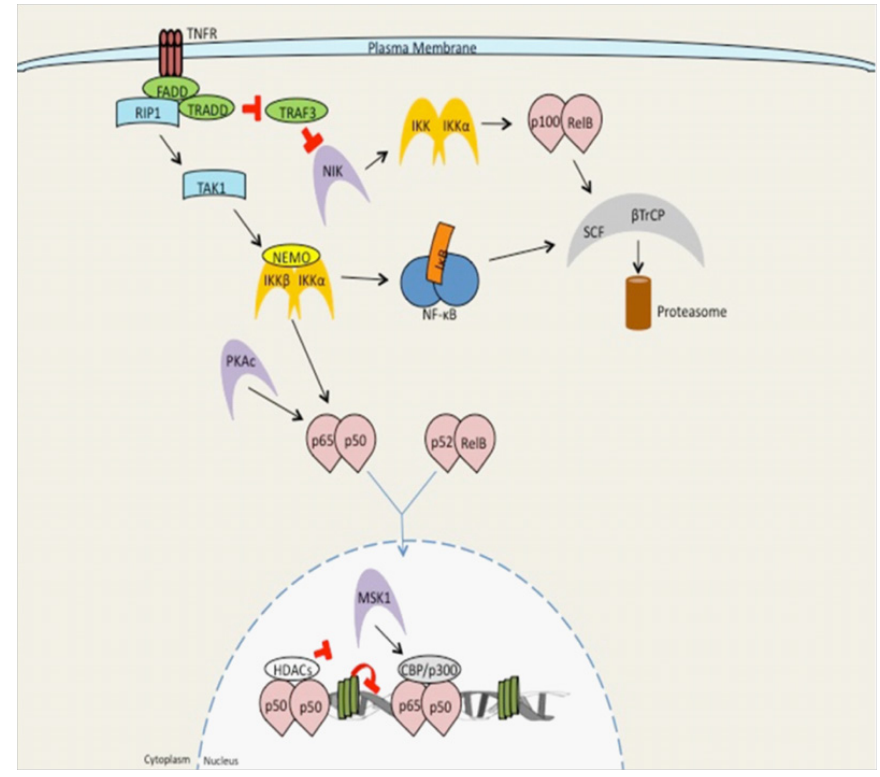

Figure I Overview of $\mathrm{NF}-\kappa \mathrm{B}$ signaling by TNF receptor signaling. Signaling by members of the TNF receptor super family, such as TNFRI, leads to recruitment of the adaptor proteins FADD andTRADD,TRAF family members (TRAF2, 5, and 6) and the kinase RIPI. The TRAF/RIP complex recruits and activates TAKI, which induces activation of the IKK complex and subsequent downstream NF- $\mathrm{B}$ B signaling. Upon stimulation, a subset of TNFR super family members that bind to TRAF3 (CD40, LT $\kappa$ R, BAFFR) induce TRAF3degradation resulting in accumulation of the kinase NIK. NIK then undergoes constitutive degradation in the absence of stimulation. Accumulated NIK phosphorylates and then activates IKKК. IKKК, thereby inducing processing of the NF- $\mathrm{BB}$ family member pl00 into $\mathrm{p} 52$. At this point $\mathrm{p} 52$-containing NF- $\kappa B$ complexes become activated (prototypically RelB: p52). Modified from Hayden et al. ${ }^{57}$

Prior to activation, NF- $\mathrm{kB}$ dimers are held in the sarcoplasm bound to inhibitory proteins, termed inhibitor of NF- $\kappa B$ (I $\mathrm{I} B){ }^{3,5,13}$ While NF$\kappa \mathrm{B}$ is bound to $\mathrm{I} \kappa \mathrm{B}$, nuclear translocation is averted, which maintains the inactive state of NF- $\kappa \mathrm{B}$ in the cytoplasm. ${ }^{5}$ However, when IкB proteins are degraded following stimulation of the cell, nuclear entry of NF- $\kappa B$ dimers becomes favoured. ${ }^{22}$ Specifically, once the cell is stimulated, the I $\kappa \mathrm{B} \alpha$ protein is quickly phosphorylated at serine 32 and 36 , which activates poly-ubiquination and degraded by the $26 \mathrm{~S}$ proteasome, thereby allowing nuclear entry of NF- $\mathrm{kB}$ dimers. ${ }^{13} \mathrm{NF}-$ $\kappa \mathrm{B}$ dimers are then free to travel to the nucleus where they bind to $\kappa \mathrm{B}$ sites within target gene promoters. NF- $\mathrm{kB}$, along with other transcription factors, then regulates transcription of genes (Figure 4) ${ }^{24}$

Activation of the NF- $\mathrm{KB}$ complex occurs in response to various stimuli, including infection, exposure to pro-inflammatory cytokines, mitogens, growth factors, biomechanical stressors, and oxidative stressors. There are several pathways by which NF-kB can be activated following ligation of different receptor families, including tumor-necrosis factor receptor (TNFR) and interleukin-1 receptor (IL$1 \mathrm{R})$. NF- $\mathrm{KB}$ complex activation also includes the activation of several intermediate kinases, including NF- $\kappa B$ inducing kinase (NIK). These intermediate kinases act as distinct signaling proteins that all unite on the IкB kinase (IKK) complex. ${ }^{5,24}$ 
A
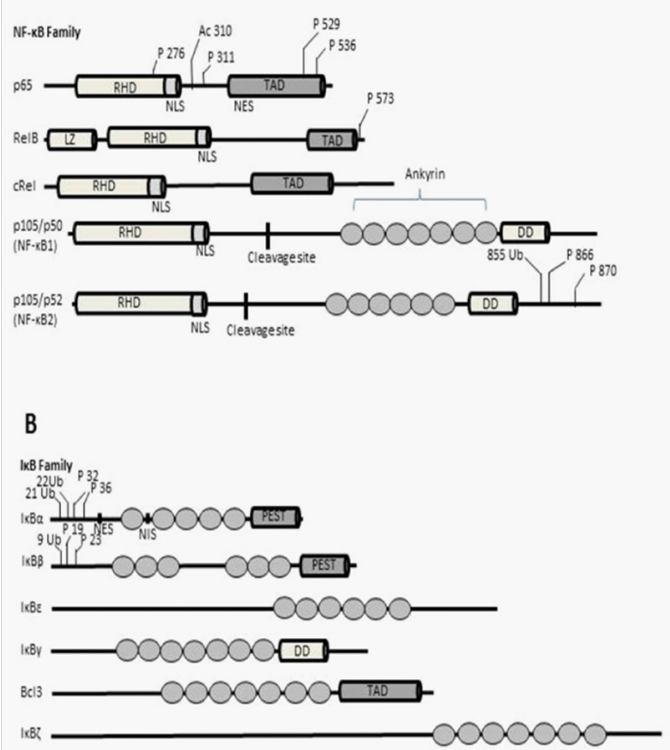

Figure $2 \ln A$, human NF- $\kappa B$ protein and in $B, I \kappa B$ proteins are illustrated. In $A$ and $B$, the specific post-translational modifications of both are also illustrated. $\mathrm{P}$, phosphorylation; Ac, acetylation; Ub, ubiquination; TAD, trans activation domain; RHD, rel homology domain; NES, nuclear export signal; NLS, Nuclear localization signal; NIS, nuclear import signal; LZ, leucine zipper; DD, death domain; Ankyrin, ankyrin repeats; PEST, polypeptide sequences enriched in proline $(\mathrm{P})$; glutamate $(\mathrm{E})$; serine $(\mathrm{S})$ and threonine $(\mathrm{T}) .^{22}$

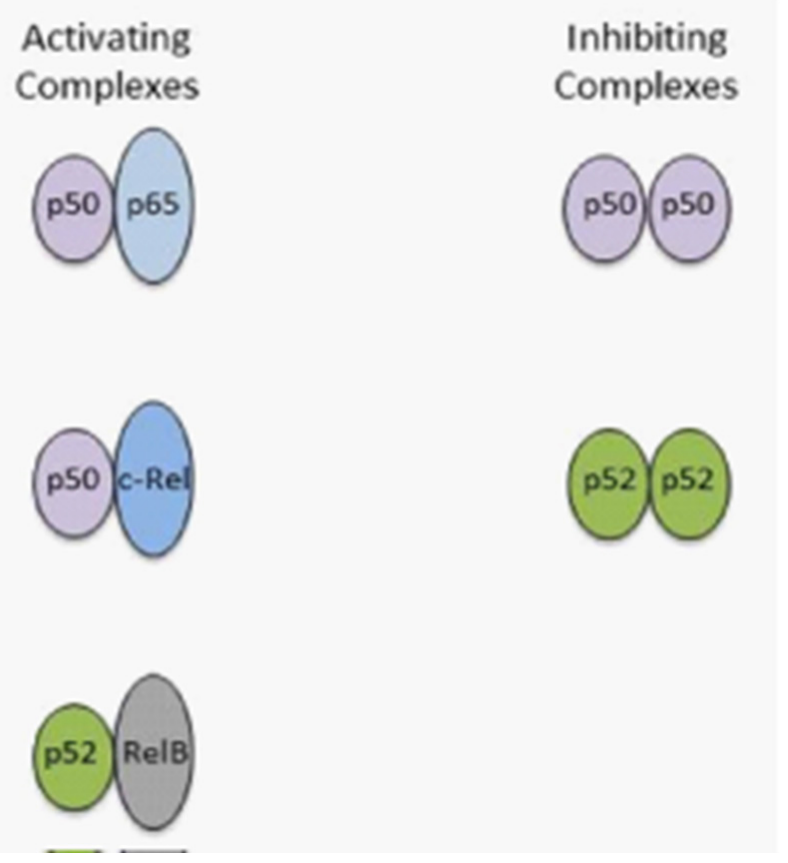

Figure 3 The NF-KB family members represented

by the activating and repressor NF-KB heterodimers.

In regard to the activating complexes, these include the $\mathrm{p} 50 / \mathrm{p} 65$, p50/c-Rel, and $\mathrm{p} 52 / \mathrm{Rel} \mathrm{B}$ heterodimers. Relative to the inhibiting complexes, these involve the $\mathrm{p} 50 / \mathrm{p} 50$ and $\mathrm{p} 52 / \mathrm{p} 52$ homodimer complexes. Contrary to the other genes, the $p 50$ and $p 52$ genes lack transcriptional activation domains, which generates $\mathrm{p} 50$ and $\mathrm{p} 52$ homodimers, and function as gene repressors by blocking DNA consensus sites. ${ }^{3}$

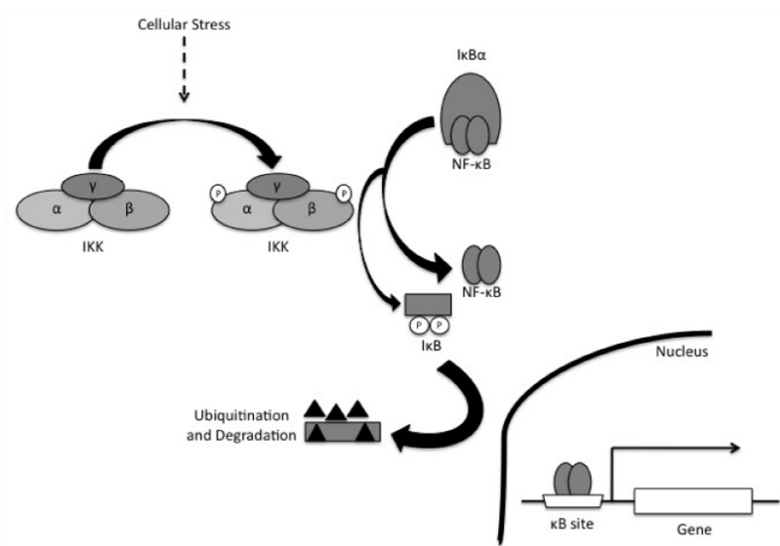

Figure 4 Activation of $I \kappa B / N F-\kappa B$ pathway by a physiological induction with stimuli such as exercise. The contraction of skeletal muscle results in transient increases in cell stress, as evidenced by the accumulation of ROS, energy depletion, etc. that induces phosphorylation of $I \kappa B \kappa$ kinase (IKK) $\kappa$. The activated IKK $\mathrm{I}$ phosphorylates the inhibitory peptide $\mathrm{I} \kappa \mathrm{B} \kappa$, thereby activating it for ubiquination and degradation by the proteasome.At this point, the freed NF- $\kappa B$ translocates to the nucleus and forms dimers to bind DNA and induce trans activation. 13

The IKK complex controls the breakdown of IкB proteins through regulation of the phosphorylation of serine 32 and 36 on I $\mathrm{I} B \alpha$, and serine 19 and 23 on IкB $\beta$. This phosphorylation results in K48-linked polyubiquitination by the SCF $\beta \operatorname{TrCPE} 3$ ubiquitin ligase complex on lysine 21 and 22 of $\mathrm{I} \kappa \mathrm{B} \alpha$, which is an ATP-dependent occurrence that quickly targets the breakdown of these proteins by the $26 \mathrm{~S}$ proteasome. ${ }^{3,22}$ To fully understand the NF- $\mathrm{KB}$ pathway, it is necessary to understand the IKK complex and its role in NF- $\kappa \mathrm{B}$ activation.

\section{IKK Complex}

The IKK complex is composed of two catalytic subunits IKK $\alpha$ / IKK1 and IKK $\beta / \mathrm{IKK} 2$, and one non-catalytic regulatory subunit IKKY/NEMO (NF- $\kappa B$ essential modulator), ${ }^{3,5,22,24,25}$ IKK $\alpha$ and IKK $\beta$ maintain a strong sequence homology, especially in their catalytic region, but differ in their specific targets. ${ }^{3,22,24}$ Both kinases enhance $\mathrm{NF}-\kappa \mathrm{B}$ trans activation potential by phosphorylation of $\mathrm{p} 65$ at serine 536. However, IKK $\beta$ can further enhance NF- $\kappa B$ activity by targeting serine 468 of p 65 . Conversely, IKK $\alpha$ phosphorylates p100 to stimulate partial proteolysis and activation of the alternative NF- $\kappa B$ pathway. ${ }^{3}$ NEMO interacts with both IKK $\alpha$ and IKK $\beta$, and associates with intermediates of upstream signaling. ${ }^{24}$

IKK complex activation requires phosphorylation of either IKKa or IKK $\beta$ on two particular serine residues within the T loop of the catalytic domain of each kinase. Unfortunately, the kinase(s) that are responsible for $\mathrm{T}$ loop phosphorylation are not known. There are two possible mechanisms that have been suggested that may be responsible for phosphorylation. The first potential mechanism is that the IKK proteins phosphorylate each other by trans-autophosphorylation, which is facilitated by either conformational changes within the IKK complex or induced proximity through oligomerization of multiple core IKK complexes. The second possible mechanism could be the existence of separate IKK-kinases that target these residues with conformational changes within the complex exposing the T loop for phosphorylation. It may even be possible that both mechanisms may happen independently or together in a nature dependent manner of the particular upstream signaling pathway (Figure 5). ${ }^{24}$ 


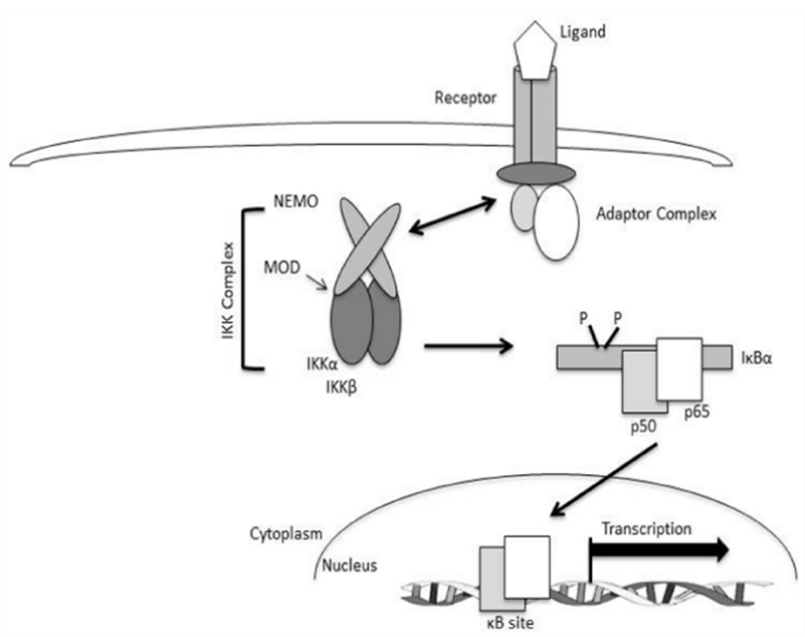

Figure 5 The NF- $\kappa B$ signaling pathway which depicts the major components of canonical signaling. The engagement of the ligand (TNF- $\kappa)$ binding to its receptor (TNFR) induces the formation of an adaptor-protein complex containing adaptor and scaffolding proteins such as TRAFs, MyD88, and TRAP, as well as kinases such as RIP and IRAK). The assembly of these protein complexes facilitates the recruitment and activation of the IKK complex through NEMO which, in turn, leads to phosphorylation and ultimately ubiquination and proteasomal degradation of $I \kappa B$ proteins. $I \kappa B$ degradation reveals a nuclear localization sequence on the $\mathrm{p} 50-\mathrm{p} 65$ heterodimer allowing them to migrate to the nucleus, bind to specific $\kappa B$-promoter sites and regulate target gene transcription. 24

Unlike the mechanisms responsible for T loop phosphorylation, the role of NEMO-induced activation of IKK has been well established. It has been determined that cells absent of NEMO are unable to activate $\mathrm{NF}-\kappa \mathrm{B}$ in response to most pro-inflammatory, immunoregulatory, and pro-survival stimuli. ${ }^{26-28} \mathrm{NEMO}$ associates with IKK $\alpha$ and IKK $\beta$ as a dimer, and can also oligomerize by a minimal oligomerization domain (MOD). Following NEMO stimulation, induced oligomerization seems to be critical for activation of IKK, and any mutations within the MOD blocks activation of IKK. ${ }^{24}$ Recently, it has been suggested that NEMO is not only an activator of IKK complex, but may also play a role in the control of IKK down-regulation through a negative interaction with IKK $\beta .{ }^{29-31}$ However, the mechanism(s) by which this occurs is not known. NEMO-induced activation of IKK, and recently the role of NEMO in repression of IKK is still the focus of ongoing research, and knowledge about NEMO-induced IKK activation and repression is continuing to develop.

\section{NF- $\kappa$ B signaling pathways}

Depending on which subunit of the IKK complex is involved, activation of NF- $\mathrm{kB}$ can occur through one of two pathways termed the classical/canonical and alternative/non-canonical pathways. ${ }^{3,5,22,24,25}$ Recent evidence has shown that both pathways can be activated in skeletal muscle, with either of these pathways capable of causing skeletal muscle wasting. ${ }^{15,16,32}$ The classical pathway is IKK $\beta$ - and IKK $\gamma$-dependent, with NF- $\kappa B$ activation occurring due to the degradation of I $\kappa \mathrm{B}$ proteins. This pathway is activated in response to inflammatory factors, bacteria, oxidative stress, leukocyte adhesion molecules, and various pro-survival genes., ${ }^{3,22,24}$ Activators of this pathway include TNF- $\alpha$, interleukin 1 (IL-1), and lipopolysaccharide (LPS), which triggers a receptor-mediated assembly of a multi-protein signaling complex, due to interaction with receptor interacting protein (RIP), that leads to activation of IKK. As a member of the TNF- receptor associated factor (TRAF) family, TRAF1-7, is at the forefront of this pathway and acts as a E3 ubiquitin ligase. TNF- $\alpha$ binds to its receptor, appropriately termed TNFR, which causes TNFR-associated death domain protein (TRADD), TRAF2, and receptor-interacting protein kinase (RIP) to be recruited. NF- $\mathrm{kB}$ activation by TRAF2, in association with cellular inhibitor of apoptosis protein (c-IAP) induces K-63 linked poly-ubiquitination of RIP, which activates TGF- $\beta$-activated kinase1 (TAK1). TAK1 then directly phosphorylates IKK, which results in the degradation of IKB proteins, and subsequent activation of the classical p50/p65 complex. ${ }^{3}$

NF- $\kappa \mathrm{B}$ can also be activated through its alternative pathway by lymphotoxin $\beta$ (LT- $\beta$ ), B-cell activating factor (BAFF), and cluster of differentiating 40 (CD40). Conversely to the classical pathway, the alternative pathway relies on IKK $\alpha$ and NF- $\mathrm{NB}$-inducing kinase (NIK), as opposed to IKK $\beta$ and RIP. ${ }^{3,5}$ NIK phosphorylates IKK $\alpha$, which results in activation and phosphorylation of I $\mathrm{KB}$ protein $\mathrm{p} 100$ on sites serine 866 and 870 . Unlike other IкB members, p100 undergoes only partial proteolysis, resulting in a functional p52 subunit. This functional p52 subunit is then released and transported to the nucleus in complex with RelB. Figure 6 depicts the two pathways of NF- $\mathrm{kB}$.

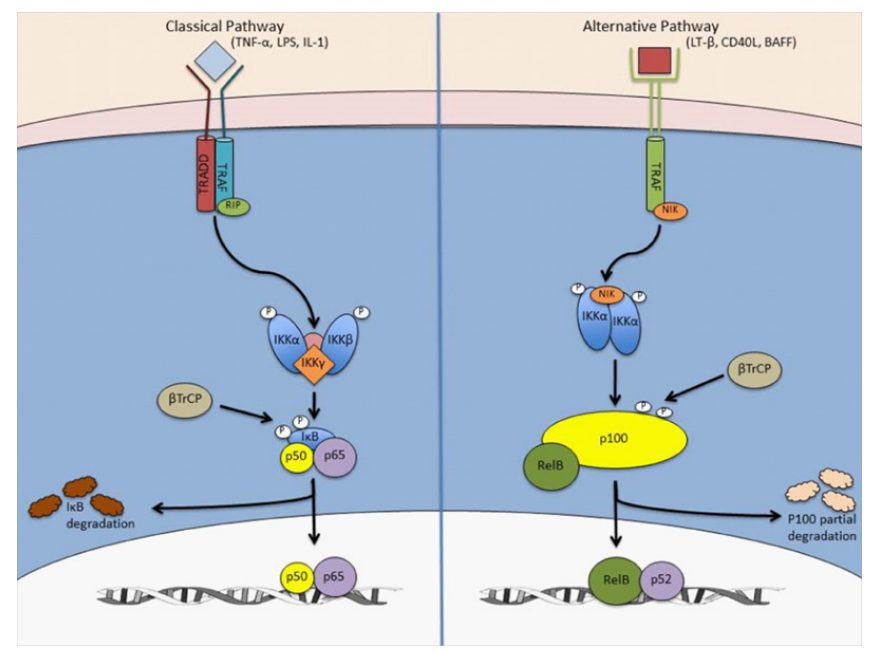

Figure 6 lassical and alternative pathways of NF- $\kappa B$ signaling pathways. The classical, canonical, signaling pathway is initiated by the binding of either TNF- $\kappa$, ILI, or LPS to its receptor and the subsequent sequential recruitment of the adaptors TRADD, RIP, and TRAF to the sarcolemma. IKK complex assembly and recruitment to the sarcolemma occurs between IKKK, IKKK, and $\mathrm{IKK} \kappa$, thereby resulting in IKK $\kappa$ phosphorylation and activation. IKK $\kappa$ then phosphorylates $I \kappa B \kappa$ to promote polyubiquination and subsequent immediate proteasomal degradation through $\kappa-\mathrm{TrCP}$. In contrast, the alternative, noncanonical, signaling pathway, the $\mathrm{p} 65 / \mathrm{p} 50$ heterodimer is free to translocate to the nuclease and mediate transcription of NFKB target genes, including one of its own inhibitor $I_{\kappa} B \kappa$. Conversely, alternative NF $\kappa B$ signaling is activated by ligands, CD40L, and lymphotoxin $\kappa$ that mediates recruitment of TRAFs to the membrane-bound receptor and subsequently activates NIK, thereby

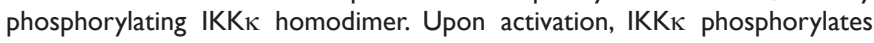
pl00 which instigates partial proteolysis by $\kappa-\operatorname{TrCP}$ to produce the $\mathrm{p} 52$ subunit. As a result, the RelB/p52 complex translocates to the nucleus to transcribe respective target genes. ${ }^{22}$

\section{Role of NF-kB in skeletal muscle}

It has been determined that murine $\mathrm{C} 2 \mathrm{C} 12$ skeletal muscle cell lines contain p65/p50 in their nucleus, which is the most commonly studied form of NF- $\mathrm{kB}$. In the myoblast cell line $\mathrm{C} 2 \mathrm{C} 12, \mathrm{NF}-\kappa \mathrm{B}$ binds on $\mathrm{\kappa B}$ sites of the cyclin $\mathrm{D} 1$ promoter. This then allows for 
transcription regulation, leading into the $\mathrm{S}$ phase of the cell cycle. During myogenesis, binding activity of NF- $\mathrm{KB}$ on cyclin D1 is decreased. This suggests that $\mathrm{NF}-\kappa \mathrm{B}$ is a critical element regulating transition to the differentiation stage from the proliferation phase. During atrophic conditions, NF- $\mathrm{kB}$ binds on the promoter of murine ring-finger-1 (MuRF1), which is an E3 ubiquitin ligase. ${ }^{25}$ This increases expression of MuRF1, suggesting NF- $\mathrm{KB}$ regulates the ubiquitin-proteasome system (UPS), resulting in muscle wasting. ${ }^{3,25}$

Another potential mechanism by which increased NF- $\mathrm{kB}$ activity leads to skeletal muscle wasting is the possibility of NF- $\mathrm{kB}$ increasing the expression of inflammation-related molecules, which either directly or indirectly enhances muscle wasting. Pro-inflammatory cytokines, including TNF- $\alpha$, THF-like weak inducer of apoptosis (TWEAK), IL-1, and IL-6 are major inducers of muscle wasting. Evidence has shown that NF- $\mathrm{KB}$ regulates expression of cytokines, chemokines, and cell-adhesion molecules ${ }^{33}$ It has also been determined that NF$\kappa \mathrm{B}$ inhibition promotes regeneration of skeletal muscle by limiting the inflammatory response. ${ }^{17}$

\section{NF- $\kappa B$ activity induced by oxidative stress and inflammation}

Various physiological stressors such as disease and exercise, which causes muscle injury, are known to induce oxidative stress. After injury, infiltrating leukocytes exert antiseptic protection of muscle by releasing reactive oxygen species (ROS) through oxidative burst activation of NADPH oxidase..$^{34}$ This process results in marked perturbations of redox status in muscle fibers. ${ }^{35}$ Consequently, pro- inflammatory cytokines, including TNF- $\alpha$, are released by neutrophils and injured muscle fibers, thereby activating ROS-generating enzymes such as xanthine oxidase. ${ }^{36}$ When ROS production is greater than the capacity of the antioxidant defense system, an oxidative stress occurs resulting in many cellular contents suffering oxidation due to ROS attack ${ }^{37}$ and subsequent activation of NF- $\kappa \mathrm{B}$, activator protein 1 (AP-1), and forkhead box (FOXO) proteins. Additionally, increased levels of ROS results in oxidation of several proteins in the excitation-contraction mechanism, ${ }^{38}$ and the production of protein reactive carbonyl derivatives lead to a loss of catalytic activity and increased vulnerability to protein breakdown. ${ }^{39}$ The effects of ROS production on signaling pathways in skeletal muscle can be seen in Figure 7.

It is well known that cellular stress is an activator of the NF- $\kappa B$ classical pathway, specifically ROS formation. Sen et al., ${ }^{40}$ were the first to demonstrate that TNF- $\alpha$-induced activation of NF- $\kappa B$ in L6 myocytes, which was augmented by conditions of oxidative stress. It was also determined that inhibition of $\mathrm{NF}-\mathrm{kB}$ activity by the antioxidant pyrrolydine dithiocarbamate, coupled with an increase in ICAM-1 expression, suggested that the intracellular redox status was critical in activation of NF- $\mathrm{KB}$, nuclear translocation, and subsequent gene transcription regulation of proteolytic genes. ${ }^{41} \mathrm{Li}$ et al., ${ }^{6}$ also found that TNF- $\alpha$ led to ROS-mediated NF- $\kappa B$ activation, resulting in a decrease of total protein in skeletal muscle with a specific loss of myosin heavy chain. The enhanced muscle protein degradation was coupled with TNF- $\alpha$-dependent stimulation of total ubiquitin conjugation of myotube proteins. ${ }^{6}$

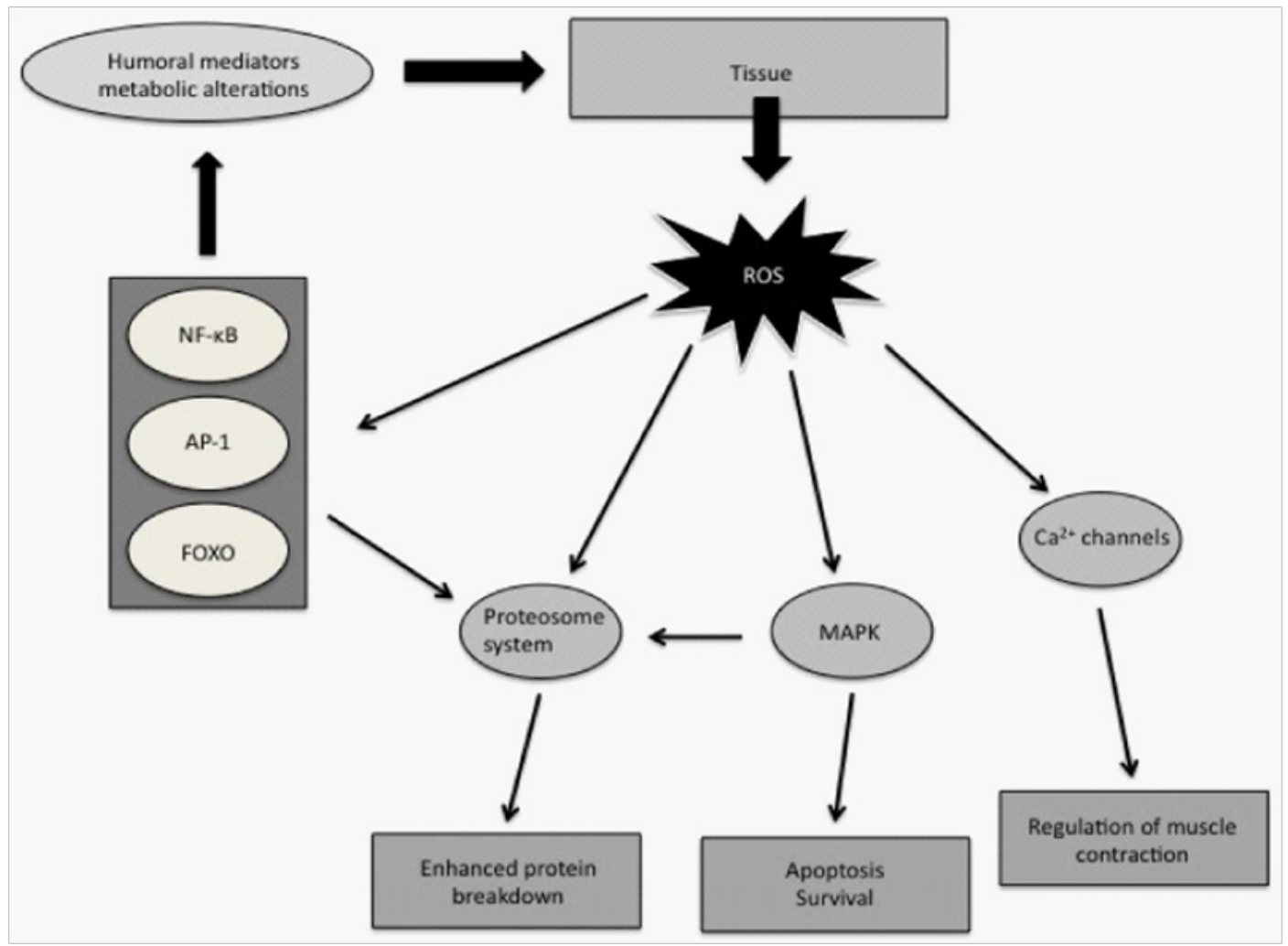

Figure 7 Effects of ROS production on skeletal muscle signaling pathways. The release of ROS from mitochondria, induced by humoral mediators such as NF- $\mathrm{KB}$, activator protein I (AP-I), and forkhead box (FOXO) proteins, or metabolic alterations results in the activation of various intracellular signaling pathways such as the proteasome system and mitogen activated protein kinase (MAPK)that collaboratively work to increase both proteolysis and cytotoxicity in the skeletal muscle. ${ }^{19}$ 


\section{Exercise-induced activation of $\mathrm{NF}=\kappa \mathrm{B}$}

Exercise causes mechanical and metabolic stresses on skeletal muscle, including an oxidative and inflammatory response. ${ }^{3}$ Various cell models have shown that increased ROS accumulation activates $\mathrm{NF}-\kappa \mathrm{B} .{ }^{42,43}$ This has led to the hypothesis that exercise may also activate NF- $\kappa \mathrm{B} .{ }^{13}$ This hypothesis has gained support because several studies $^{44-48}$ have shown that, in addition to calcineurin-nuclear $\mathrm{T}$ factor of activated $\mathrm{T}$ cells (NFAT) signaling and heat shock proteins (HSPs), NF- $\kappa \mathrm{B}$ can be also be activated with exercise. Ji et al., ${ }^{46}$ determined that rats exercised to exhaustion had increased levels of $\mathrm{NF}-\kappa \mathrm{B}$ activation when compared to control. Ho et al., ${ }^{44}$ also reported an increase of NF- $\mathrm{kB}$ activity by $50 \% 1-3$ three hours following a 60 minute treadmill running bout. As much as a $76 \%$ decrease in IKK phosphorylation was also seen. Another mechanism suggested due to exercise is that acute exercise may cause oxidation of glutathione in skeletal muscle, which results in increased oxidative stress and NF$\kappa \mathrm{B}$ activation. ${ }^{49}$ Evidence from this example suggests that regular exercise may increase glutathione levels in skeletal muscle, resulting in a down-regulation of NF- $\mathrm{BB}$ activity. ${ }^{41}$ However, there have been a few studies that have shown that exercise causes a down-regulation of NF- $\kappa B$ activity. ${ }^{32,50,51}$ While the majority of evidence favors exerciseinduced NF- $\mathrm{KB}$ activity, more research needs to be completed to determine why there are some discrepancies in the research. The relationship between exercise, ROS, and RONS (reactive oxygen nitrogen species) can be seen in Figure 8.

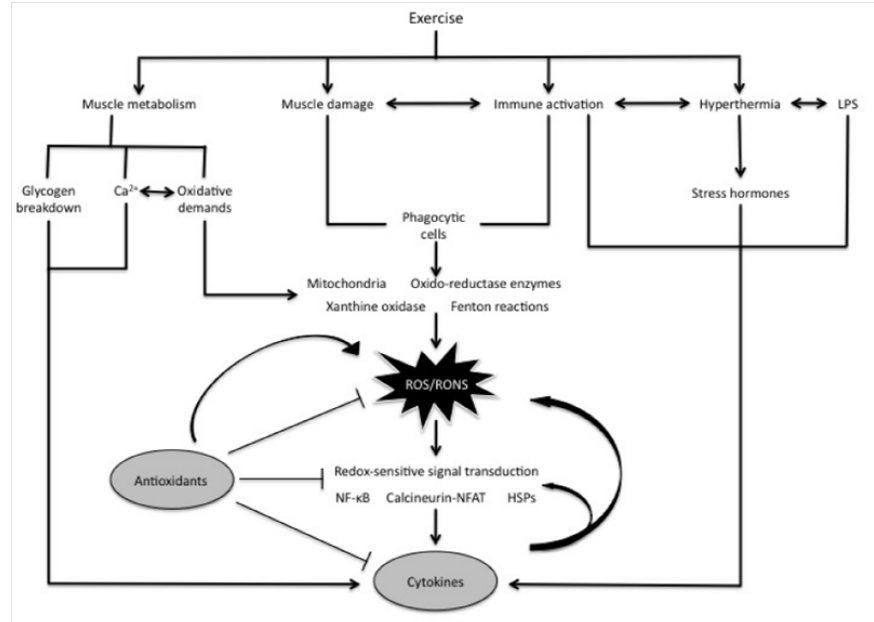

Figure 8 Interactions between exercise, ROS/RONS, antioxidants, and cytokines. Exercise causes mechanical and metabolic stresses on skeletal muscle, thereby inducing an oxidative and inflammatory response. As a result, ROS accumulation occurs and activates NF- $\kappa B$, in addition to calcineurinnuclear $T$ factor of activated T cells (NFAT) signaling and heat shock proteins (HSPs). ${ }^{20}$

\section{Antioxidant nutraceutical supplementation and NF- $K B$}

Antioxidant supplementation has been suggested to attenuate exercise-induced oxidative stress. Redox regulation of cytokine production occurs at multiple levels, including the activation of oxidant-sensitive and redox-sensitive NF- $\kappa B^{52}$ Anti-oxidant supplementation has been show to attenuate NF- $\mathrm{KB}$, activated by ROS associated with exercise-induced muscle damage ${ }^{53}$ and RONS. ${ }^{54}$ Aoi et al. ${ }^{53}$ demonstrated in rats that a 3 -week diet high in $\alpha$-tocopherol $(500 \mathrm{mg} / \mathrm{kg})$ attenuated NF- $\mathrm{kB}$ activation and $\mathrm{p} 65$ nuclear translocation following treadmill running for $60 \mathrm{~min}$ at a speed of $25 \mathrm{~m} / \mathrm{min}$. This study showed there is a relationship between ROS and NF- $\kappa B$ and that supplementation of the antioxidant $\alpha$-tocopherol was able to inhibit oxidative stress and NF- $\mathrm{KB}$ activation. Vassilakopoulas et al. ${ }^{55}$ investigated the effect of a multiple antioxidant supplement (vitamins E, A, C for 60days and $\mathrm{N}$-acetyl cysteine for 3days) in healthy males on plasma cytokine concentrations following bicycle exercise for 45 minutes at $70 \%$ of maximum oxygen consumption. They determined, compared to pre-supplementation, that antioxidant supplementation abolished the exercise-induced increase in circulating TNF- $\alpha$. Michailidis et al., ${ }^{56}$ showed that the thiol-based antioxidant $\mathrm{N}$-acetyl cysteine provided orally to men at a dose of $200 \mathrm{mg} / \mathrm{kg} /$ day for 8 days effectively attenuated circulating proinflammatory cytokines and skeletal muscle NF- $\mathrm{kB}$ phosphorylation following muscle damaging exercise (300 eccentric contractions).

\section{Conclusion}

The information presented herein indicates that various antioxidant nutraceuticals can play a beneficial role in attenuating oxidative stress and the subsequent increase in circulating TNF- $\alpha$ and canonical $\mathrm{NF}-\kappa \mathrm{B}$ signaling occurring in response to exercise-induced muscle damage. Since the downstream consequences of exercise-muscle damage are similar to those associated with various pathologic conditions involving muscle wasting, the implications from this review are noteworthy. Inhibition of NF- $\mathrm{BB}$ pathway activity has been shown to attenuate muscle wasting through various mechanisms; however, there is still conflicting evidence and more research needs to be completed to fully elucidate the role of NF- $\mathrm{kB}$ signaling in skeletal muscle. Antioxidant supplementation has been shown to attenuate oxidative stress and the subsequent formation of ROS/RONS production in skeletal muscle. Furthermore, this area requires further research as this process has also been demonstrated to mediate NF- $\kappa B$ signaling. Research on NF- $\mathrm{kB}$ signaling in skeletal muscle is a rapidly growing area of interest, and advances in this area may affect the types of nutraceutical supplements ingested with the intent of maintaining muscle mass during periods of heightened inflammation and oxidative stress and possible muscle wasting.

\section{Acknowledgments}

This brief review project was not partially or fully sponsored by any external sponsoring agent, rather support was provided by the Department of Health, Human Performance, and Recreation of Baylor University.

\section{Conflict of interest}

Author declares that there is no conflict of interest.

\section{References}

1. Kerksick CM, Kreider RB, Willoughby DS. Intramuscular adaptations to eccentric exercise and antioxidant supplementation. Amino Acids. 2010;39(1):219-232.

2. Guo W, Kong E, Meydani M. Dietary polyphenols, inflammation, and cancer. Nutr Cancer. 2009;61(6):807-10.

3. Peterson JM, Bakkar N, Guttridge DC. NF-KB Signaling in Skeletal Muscle Health and Disease. Curr Top Dev Biol. 2011;96:85-119.

4. Evans WJ. Vitamin E, vitamin C, and exercise. Am J Clin Nutr. 2000;72(Suppl 2):647S-652S.

5. Li H, Malhotra S, Kumar A. Nuclear factor-kappa B signaling in skeletal muscle atrophy. J Mol Med (Berl). 2008;86(10):1113-1126. 
6. Li YP, Schwartz RJ, Waddell ID, et al. Skeletal muscle myocytes undergo protein loss and reactive oxygen-mediated NF-kappaB activation in response to tumor necrosis factor alpha. FASEB $J$. 1998;12(10):871-880.

7. Bhatnagar S, Panguluri SK, Gupta SK, et al. Tumor necrosis factoralpha regulates distinct molecular pathways and gene networks in cultured skeletal muscle cells. PLoS One. 2010;5(10):e13262.

8. Dogra $\mathrm{C}$, Changotra $\mathrm{H}$, Wedhas $\mathrm{N}$, et al. TNF-related weak inducer of apoptosis (TWEAK) is a potent skeletal muscle-wasting cytokine. FASEB J. 2007;21(8):1857-1869.

9. Reid MB, Li YP. Tumor necrosis factor-alpha and muscle wasting: a cellular perspective. Respir Res. 2001;2(5):269-272.

10. Jackman RW, Kandarian SC. The molecular basis of skeletal muscle atrophy. Am J Physiol Cell Physiol. 2004;287(4):C834-C843.

11. Ventadour S, Attaix D. Mechanisms of skeletal muscle atrophy. Curr Opin Rheumatol. 2006;18(6):631-635.

12. Eley HL, Tisdale MJ. Skeletal muscle atrophy, a link between depression of protein synthesis and increase in degradation. $J$ Biol Chem. 2007;282(10):7087-7097.

13. Kramer HF, Goodyear LJ. Exercise, MAPK, and NF-kappaB signaling in skeletal muscle. J Appl Physiol. 2007;103(1):388-395.

14. Acharyya S, Villalta SA, Bakkar N, et al. Interplay of IKK/NF-kappaB signaling in macrophages and myofibers promotes muscle degeneration in Duchenne muscular dystrophy. J Clin Invest. 2007;117(4):889-901.

15. Cai D, Frantz JD, Tawa NE, et al. IKKbeta/NF-kappaB activation causes severe muscle wasting in mice. Cell. 2004;119(2)285-298.

16. Hunter RB, Kandarian SC. Disruption of either the Nfkb1 o the $\mathrm{Bcl} 3$ gene inhibits skeletal muscle atrophy. $J$ Clin Invest. 2004;114(10):1504-1511.

17. Mourkioti F, Kratsios P, Luedde T, et al. Targeted ablation of IKK2 improves skeletal muscle strength, maintains mass, and promotes regeneration. J Clin Invest. 2006;116(11):2945-2954.

18. Sakkas GK, Schambelan M, Mulligan K. Can the use of creatine supplementation attenuate muscle loss in cachexia and wasting? Curr Opin Clin Nutr Metab Care. 2009;12(6):623-627.

19. Bonetto A, Penna F, Muscaritoli M, et al. Are antioxidants usefu for treating skeletal muscle atrophy? Free Radic Biol Med. 2009;47(7):906-916.

20. Peake JM, Suzuki K, Coombes JS. The influence of antioxidant supplementation on markers of inflammation and the relationship to oxidative stress after exercise. J Nutr Biochem. 2007;18(6):357-371.

21. Ringseis R, Keller J, Eder K. Mechanisms underlying the anti-wasting effect of L-carnitine supplementation under pathologic conditions: evidence from experimental and clinical studies. Eur J Nutr. 2013;52(5):1421-1442.

22. Bakkar N, Guttridge DC. NF-kappaB signaling: a tale of two pathways in skeletal myogenesis. Physiol Rev. 2010;90(2):495-511.

23. Pahl HL. Activators and target genes of Rel/NF-kappaB transcription factors. Oncogene. 1999;18(49):6853-6866

24. Solt LA, May MJ. The IkappaB kinase complex: master regulator of NF-kappaB signaling. Immunol Res. 2008;42(1-3):3-18.

25. Mourkioti F, Rosenthal N. NF-kappaB signaling in skeletal muscle: prospects for intervention in muscle diseases. $J$ Mol Med (Berl). 2008;86(7):747-759

26. Makris C, Godfrey VL, Krahn-Senftleben G, et al. Female mice heterozygous for IKK gamma/NEMO deficiencies develop a dermatopathy similar to the human X-linked disorder incontinentia pigmenti. Mol Cell. 2000;5(6):969-979.
27. Rudolph D, Yeh WC, Wakeham A, et al. Severe liver degeneration and lack of NF-kappaB activation in NEMO/IKKgamma-deficient mice. Genes Dev. 2000;14(7):854-862.

28. Yamaoka S, Courtois G, Bessia C, et al. Complementation cloning of NEMO, a component of the IkappaB kinase complex essential for NFkappaB activation. Cell. 1998;93(7):1231-1240.

29. Delhase M, Hayakawa M, Chen Y, et al. Positive and negative regulation of IkappaB kinase activity through IKKbeta subunit phosphorylation. Science. 1999;284(5412):309-313.

30. May MJ, Marienfeld RB, Ghosh S. Characterization of the Ikappa B-kinase NEMO binding domain. $J$ Biol Chem. 2002;277(48):45992-46000.

31. Schomer-Miller B, Higashimoto T, Lee YK, et al. Regulation of IkappaB kinase (IKK) complex by IKKgamma-dependent phosphorylation of the T-loop and C terminus of IKKbeta. J Biol Chem. 2006;281(22):15268-15276

32. Hunter RB, Stevenson E, Koncarevic A, et al. Activation of an alternative NF-kappaB pathway in skeletal muscle during disuse atrophy. FASEB J. 2002;16(6):529-538.

33. Kumar A, Takada Y, Boriek AM, et al. Nuclear factor-kappaB: its role in health and disease. J Mol Med (Berl). 2004;82(7):434-448.

34. Hayden MS, West AP, Ghosh S. Snap Shot: NF-kappaB signaling pathways. Cell. 2006;127(6):1286-1287.

35. Nikolaidis M, Jamurtas A, Paschalis V, et al. The effect of muscledamaging exercise on blood and skeletal muscle oxidative stress: magnitude and time-course considerations. Sports Med. 2008;38(7):579-606

36. Ji LL, Gomez-Cabrera MC, Vina J. Role of nuclear factor kappaB and mitogen-activated protein kinase signaling in exerciseinduced antioxidant enzyme adaptation. Appl Physiol Nutr Metab. 2007;32(5):930-935.

37. Smolka MB, Zoppi CC, Alves AA, et al. HSP72 as a complementary protection against oxidative stress induced by exercise in the soleus muscle of rats. Am J Physiol Regul Integr Comp Physiol. 2000;279(5):R1539-R1545.

38. Brotto MA, Nosek TM. Hydrogen peroxide disrupts $\mathrm{Ca} 2^{+}$release from the sarcoplasmic reticulum of rat skeletal muscle fibers. $J$ Appl Physiol (1985). 1996;81(2):731-737.

39. Radak Z, Kaneko T, Tahara S, et al. The effect of exercise training on oxidative damage of lipids, proteins, and DNA in rat skeletal muscle: evidence for beneficial outcomes. Free Radic Biol Med 1999;27(1-2):69-74.

40. Sen CK, Khanna S, Reznick AZ, et al. Glutathione regulation of tumor necrosis factor-alpha-induced NF-kappa B activation in skeletal musclederived L6 cells. Biochem Biophys Res Commun. 1997;237(3):645-649.

41. Bar-Shai M, Carmeli E, Ljubuncic P, et al. Exercise and immobilization in aging animals: the involvement of oxidative stress and NF-kappaB activation. Free Radic Biol Med. 2008;44(2):202-214.

42. Kamata $\mathrm{H}$, Manabe $\mathrm{T}$, Oka $\mathrm{Si}$, et al. Hydrogen peroxide activates IkappaB kinases through phosphorylation of serine residues in the activation loops. FEBS Lett. 2002;519(1-3):231-237.

43. Muller JM, Rupec RA, Baeuerle PA. Study of gene regulation by NF-kappa B and AP-1 in response to reactive oxygen intermediates. Methods. 1997;11(3):301-312.

44. Ho RC, Hirshman MF, Li Y, et al. Regulation of IkappaB kinase and NF-kappaB in contracting adult rat skeletal muscle. Am J Physiol Cell Physiol. 2005;289(4):C794-C801.

45. Hollander J, Fiebig R, Gore M, et al. Superoxide dismutase gene expression is activated by a single bout of exercise in rat skeletal muscle. Pflugers Arch. 2001;442(3):426-434. 
46. Ji LL, Gomez-Cabrera MC, Steinhafel N, et al. Acute exercise activates nuclear factor (NF)-kappaB signaling pathway in rat skeletal muscle. FASEB J. 2004;18(13):1499-1506.

47. Ji LL, Gomez-Cabrera MC, Vina J. Exercise and hormesis: activation of cellular antioxidant signaling pathway. Ann N Y Acad Sci. 2006; 1067:425-435

48. Spangenburg EE, Brown DA, Johnson MS, et al. Exercise increases SOCS-3 expression in rat skeletal muscle: potential relationship to IL-6 expression. J Physiol. 2006;572(Pt 3):839-848.

49. Sen CK. Glutathione homeostasis in response to exercise training and nutritional supplements. Mol Cell Biochem. 1999;196(1-2):31-42.

50. Durham WJ, Li YP, Gerken E, et al. Fatiguing exercise reduces DNA binding activity of NF-kappaB in skeletal muscle nuclei. J Appl Physiol. 1985;97(5):1740-1745

51. Durham WJ, Arbogast S, Gerken E, et al. Progressive nuclear factorkappaB activation resistant to inhibition by contraction and curcumin in mdx mice. Muscle Nerve. 2006;34(3):298-303.
52. Haddad JJ. Pharmaco-redox regulation of cytokine-related pathways From receptor signaling to pharmacogenomics. Free Radic Biol Med. 2002;33(7):907-926.

53. Aoi W, Naito Y, Takanami Y, et al. Oxidative stress and delayedonset muscle damage after exercise. Free Radic Biol Med. 2004;37(4):480-487.

54. Kosmidou I, Vassilakopoulos T, Xagorari A, et al. Production of interleukin- 6 by skeletal myotubes: Role of reactive oxygen species. Am J Respir Cell Mol Biol. 2002;26(5):587-593.

55. Vassilakopoulos T, Karatza MH, Katsaounou P, et al. Antioxidants attenuate the plasma cytokine response to exercise in humans. $J$ Appl Physiol (1985). 2003;94(3):1025-1032.

56. Michailidis Y, Karagounis LG, Terzis G, et al. Thio-based antioxidant supplementation alters human skeletal muscle signaling and attenuates its inflammatory reponse and recovery after intense exercise. Am J Clin Nutr. 2013;98(1):233-245. 